\title{
What changes should I make in my lifestyle?
}

\author{
DESMOND J LEDDIN, MRCPI, MSC, FRCPC, C NOEL WILLIAMS, MD, FACG, FACP, FRCPC
}

$\mathrm{F}$ ROM THE PHYSICIAN'S VIEWPOINT, an appreciation of the effect of inflammatory bowel disease (IBD) on lifestyle is important not only because it is part of good patient care, but also because an understanding of the overall impact of the disease may explain an individual's use of the health care system (1). Furthermore, IBD should not be viewed solely in the dimension of treatment and prognosis but in the multidimensional context of the individual's lifestyle. It is the interaction of disease activity, cultural and familial behaviour, psychological status, coping mechanisms, social support and stress which determine health status (2). Individuals with comparable disease activity may react very differently (3), indicating that lifestyle issues are important determinants of health.

From the viewpoint of the individual with the disease, two questions may arise. First, there may be concern with regard to the impact of the disease on lifestyle. Second, there is concern that specific lifestyle issues, such as smoking, may have an impact on the disease.

This review deals not with the 'medical' aspects of IBD but with its effect on lifestyle and consequently with the issue of whether alterations may be required.

Lifestyle is defined as all of those factors which contribute to the way people live, namely family and marital relationships, social activities, education and work. In addition some personal habits such as smoking and oral contraceptive use may be relevant.

\section{EFFECT OF IBD ON LIFESTYLE}

The age of onset of IBD coincides with the time when individuals are entering the workplace or developing their careers. Active disease with the associated symptoms of fatigue, arthritis, bowel urgency and the effect of medications has the potential to severely curtail career plans and to cause problems when pursuing an active career. Availability of washrooms may become a major issue in determin-

Division of Gastroenterology, Victoria General Hospital, Dalhousie University, Halifax, Nova Scotia

Correspondence and reprints: Dr DJ Leddin, Dickson Centre, Room 4087, Victoria General Hospital, Halifax, Nova Scotia B3H 2Y9. Telephone (902) 428-2397

ing work and social activity (4). Even when the disease is in remission the unpredictability of relapses (5) may affect long term planning.

Will I be able to work? Individuals who develop the disease before becoming employed may be concerned that their employment prospects will be decreased. The percentage of patients with Crohn's disease who are employed has been shown to be no different from a control population (6). In a sample of 170 patients with ulcerative colitis and Crohn's disease in Birmingham, United Kingdom (3), only $5 \%$ were unemployed, a percentage considerably less than the $15.5 \%$ unemployment rate in the region at that time.

In a different manner investigators from Denmark (7) studied the capacity for work, ie, the potential ability to work, of 783 patients diagnosed with ulcerative colitis between 1960 and 1978. Fully capable was defined as requiring less then one month off through sickness during the year, and partly capable was defined as one month or more but less than 11 months lost through sickness during the year. Incapable was defined as in work for less than one month during the year. Apart from the year following diagnosis 
the capacity for work was excellent. About $90 \%$ of patients with ulcerative colitis were fully capable of work after the first year. Approximately equal numbers of the remainder were partly capable or incapable of work. There was no difference in capacity to work between those patients who underwent colonic resection and those who did not.

The same group (8) looked at 185 patients diagnosed with Crohn's disease between 1960 and 1978. Here the situation was somewhat different from that in ulcerative colitis. In contrast to the $90 \%$ of ulcerative colitis patients fully capable of work following the year of diagnosis, about $75 \%$ of patients with Crohn's were fully capable of working. Five to 10 years following diagnosis of Crohn's disease about $15 \%$ of all patients with this disease were unable to work.

These discouraging data have not been substantiated. A study on 106 patients with Crohn's disease and a control group of 75 previously healthy patients admitted to hospital in Copenhagen for acute illness has been reported (6). Sixty-five per cent of Crohn's disease patients were employed. This contrasted with $64 \%$ of controls and was therefore not sig. nificantly different. Six per cent of the Crohn's disease patients and 7\% of the controls were unemployed.

It is clear that an individual with IBD is able to work. The vast majority of patients with either ulcerative colitis or Crohn's disease are fully capable of employment if they so wish.

Will I be able to work well? Getting a job and successfully functioning in that job are clearly different issues. The systemic symptoms which accompany IBD are a major concern of patients (9) and it is clear that these symptoms do take a toll on one's ability to function. Fiftyfour per cent of patients with Crohn's disease felt that exacerbations of the disease strained their professional life (6). Twenty-eight per cent of patients in the Birmingham study felt that symptoms of malaise and arthritis caused problems at work (3). Nevertheless only small numbers $(6 \%)$ felt that there was a major restriction in their range of occupation.
Nearly three-quarters of the patients with Crohn's disease had lost less than 11 work days in the previous year and this was no different from the control population (6). The data from Birmingham are very similar (3). In that study $55 \%$ of patients had lost no time off at all in the year prior to the survey (10).

Clearly IBD is a significant illness but employers (and individuals with the disease) should be reassured that absence due to sickness is no different from that in the general population. The data indicate that individuals with IBD are fully capable of working well.

The continuity of employment of patients with Crohn's disease may actually be better than that of the general population (6). In the Birmingham study continuity was also good, with $57 \%$ of patients remaining with the same employers.

Will I need to make changes in my work habits? Any major life event may precipitate an evaluation of one's life and lifestyle. Many patients with IBD recognize that the activity of the disease is only one factor which contributes to their overall well-being and many do make changes in their work habits. Over $40 \%$ of patients in the Birmingham study either changed the type of work in which they were involved or modified their hours (3). This cannot be explained by inability to work since this does not differ from the general population, and it may suggest that a re-evaluation of lifestyle goals has taken place.

Will I need to retire early? In patients with ulcerative colitis, less than $5 \%$ required a disability pension (6) and virtually none required this because of the IBD. Only two of 13 patients who retired in the Birmingham study did so because of ill health (3). In patients with Crohn's disease the numbers requiring disablement pension are similar (6). Early retirement because of disability does not seem to occur with increased frequency in IBD.

Attitude of colleagues and employer: While not precisely an aspect of lifestyle, the response of an employer or work colleagues may be a determinant of work satisfaction. The attitude of colleagues was generally helpful $(80 \%)$ or neutral (18\%) (3). Approximately the same pattern of response was elicited from employers on disclosure of the disease. Individuals with IBD may fear that disclosure of the disease will affect promotion or result in demotion or other forms of discrimination. Fortunately discrimination, failure of promotion or demotion are uncommon $(3,18)$.

Will IBD affect my education? There is little information available on whether onset of the disease in childhood and adolescence affects subsequent educational and career choices. Probably for the majority of children and adolescents with the disease there is little impact but there will remain some who miss significant time from school.

The educational level of patients with ulcerative colitis has been found to be no different (12) or higher than a control population (13). A similar trend may be seen in Crohn's disease patients $(6,13)$.

Recent data from Alberta indicate that educational level does influence the prevalence of IBD. In both Crohn's disease and ulcerative colitis, the highest prevalence was seen in individuals with university degrees. The authors speculated that the connection between educational level and IBD may be that individuals with higher educational levels may have different lifestyles and diet than those lesser educated.

The question of whether a diagnosis of IBD will affect subsequent educational level cannot be answered at present, but available data indicate that the educational level of patients with IBD is actually higher than, or the same as, that of the general population.

Will IBD affect my ability to function socially? Worries with regard to impaired social functioning are not ranked, particularly in patients with IBD (9). Some authors have reported an increased risk of psychosocial impairment in Crohn's disease (15). However, in a comparison of individuals with Crohn's with controls no difference in social activity was seen (6). The IBD group functioned perfectly well with regard to cultural, sporting, educational and social events. Nevertheless, between $17 \%$ (16) and $21 \%$ (6) felt that their social and leisure ac- 
tivities were impaired to some degree. This hardly is surprising in a disease which is chronic and which may relapse unpredictably.

In one study, patients with distal ulcerative colitis, even when symptoms were minimal, had restricted social and leisure activities (11).

Individuals with IBD should be reassured that there is good evidence to suggest that social function is normal for the vast majority, although the disease may impose some restrictions at times.

Will IBD affect my marital status? In a study of patients with Crohn's disease no difference was seen in the number of patients married or cohabiting compared with a control population (6). The results of a multicentre European survey were very similar (17). There is no evidence to suggest that the marital status of patients with IBD is any different from that of the population as a whole.

In a survey of Crohn's disease over twice as many patients felt that their marriage had improved as a result of the diagnosis compared with those that felt the diagnosis had a deleterious effect (18). Most patients felt that the diagnosis had resulted in a closer understanding between themselves and spouses. Similarly, in patients with ulcerative colitis, one-third felt that their marriage was strengthened by the difficulties of the illness (11).

Does IBD affect sexual function? Seventeen per cent of respondents in a survey of Canadian Foundation for Ileitis and Colitis members in British Columbia reported that IBD affected their sexuality (9). Furthermore, loss of sex drive and inability to perform sexually was listed as a concern in about one-third of patients with these diseases (15).

Sexual problems have been reported to occur frequently in patients with Crohn's disease and the degree of sexual dysfunction has been shown to correlate with marital difficulties (18). On the other hand no difference between IBD and controls in the percentage experiencing sexual difficulties was reported in a European study (6).

It would appear that IBD may affect sexual function and that in some cases this may lead to marital problems. The finding from the United Kingdom that a diagnosis of IBD may actually bring a couple closer together is encouraging. What is the effect of surgery on lifestyle? Worries about surgery are a major concern of individuals with IBD (9). Fear of an ostomy ranks as a greater concern then development of cancer or inability to attend work or school regularly (15). Between 6 and $9 \%$ of patients with ulcerative colitis will require an operation in the first year and perhaps as many as one-third will be operated upon within 18 years $(7,19)$. The figures for Crohn's disease are higher. Seventy per cent of patients with onset of the disease before the age of 20 will require surgery (26), regardless of the pattern of disease. In adults about one-third will require an operation in the year following diagnosis and as many as $55 \%$ by 10 years (8).

Surgery may result in changes in work in a high proportion of patients $(3,10)$. The type of surgery is important with changes being most common after total colonic removal and ileostomy. The amount of time off work after surgery also is related to the type of operation. The longest absences were seen in those who had an ileostomy after colonic resection (10). Fifty per cent of this group were back at work by six months. In comparison, 65\% of patients with segmental resection were back by three months after surgery.

Surgery results in changes in work in a considerable proportion of patients. However, the effect of surgery on lifestyle has been shown to be very beneficial with almost all patients reporting an improvement compared with their presurgical state (21). The beneficial effect of surgery on symptoms has been reported previously (22).

In children and adolescents with ileostomies no difference was found compared with children with ileorectal anastomosis or those without surgery with regard to psychological adjustment, self-esteem, quality of life or sexual behaviour (23).

Individuals with ileostomies were found to have higher overall dysfunction and a slightly higher number reported a negative body image than those without (21). The functional status in relation to work following ileostomy appears to be excellent, however (3). Patients with ileostomies average about two sick days from work per year (24).

In part because of the negative perception of ostomies, several surgical techniques have been developed to obviate the need for a stoma. In general, patient satisfaction with either the continent reservoir (25) or the pelvic pouch procedures (26) is greater than is seen with ileostomy.

Surgery may therefore result in significant changes in work patterns, with many patients altering their hours or type of work. Surgery is associated with an overall increase in well-being. Although ileostomy may result in problems, the functional status is excellent and the majority of patients consider that stoma formation has no effect or is beneficial to their work performance (3). Patient satisfaction with the newer surgical techniques is high.

\section{EFFECT OF LIFESTYLE ON IBD}

The issue of whether IBD can affect lifestyle has been discussed and reference was made to the effect of educational level on prevalence of IBD. It has become apparent that two other lifestyle issues are of importance, namely smoking and oral contraceptives.

Should I stop smoking? It is a common clinical experience to obtain a history of ex-smoking in patients presenting with ulcerative colitis. Smokers are about three times less likely to develop ulcerative colitis than nonsmokers (27). Ex-smokers, however, are at even greater risk of developing ulcerative colitis than if they never started.

In contrast to the situation in ulcerative colitis (where smoking seems to protect against the disease) smoking doubles the risk of developing Crohn's disease. Discontinuation of smoking reduces the risk of developing the disease (27) and may reduce the frequency of reoperation (28).

Smoking produces changes in both the cellular and humoral immune systems (28) and may alter intestinal permeability. How these changes affect the development and behaviour of IBD is unknown and it is unclear why the 
effect is opposite in ulcerative colitis and Crohn's disease.

It seems reasonable to advise patients with Crohn's disease to discontinue smoking, not only because of the effects of smoking on cardiovascular and respiratory mortality, but also because Crohn's disease may follow a more aggressive course in patients who continue to smoke (29).

The situation with regard to ulcerative colitis developing in ex-smokers is more difficult. For the vast majority of patients who develop the disease after stopping, the long term risk and inconvenience of controlling the disease with conventional therapy will greatly outweigh the excess mortality and morbidity associated with smoking. There will be a small number of ex-smokers with difficult disease who require either immunosuppressive agents or colectomy. The options should be discussed with the patient. There are anecdotal reports of nicotine chewing gum being effective and it may be reasonable to try this. There is no convincing evidence to support this approach.

Is it safe to use oral contraceptives? Occasionally young women taking oral contraceptives are seen with a Crohn'slike disease which appears to resolve

\section{REFERENCES}

1. Drossman DA, Mitchell CM, Leserman J, Patrick DL, Zagami EA, Li Z. Psychosocial and disease predictors of utilization in IBD. Gastroenterology 1990;98:Al67.

2. Garrett JW, Drossman DA. Health status in inflammatory bowel disease. Gastroenterology 1990;99:90.

3. Wyke RJ, Edwards FC, Allan RN. Employment problems and prospects for patients with inflammatory bowel disease. Gut 1988;29:1229.

4. Foston LR. A patient's view of ileostomy. The Professional Nurse 1989;Oct:20-1.

5. Sachar DB. Predicting relapses of Crohn's disease: Clouds in the crystal ball. Dig Dis Sci 1987;32:206.

6. Sorensen VZ, Olsen BG, Binder V. Life prospects and quality of life in patients with Crohn's disease. Gut 1987;28:382.

7. Hendriksen C, Kreiner S, Binder V. Long term prognosis in ulcerative colitis - based on results from a regional patient group from the county of Copenhagen. Gut 1985;26:158. following discontinuation of the contraceptives and institution of standard treatment. One of the authors has followed one such patient for four years following presentation with severe Crohn's-like disease of the ileum and right colon. There has been no relapse. This would be unusual for Crohn's disease but possible.

Oral contraceptives are associated with an increased risk of thromboembolic disease. The early aphthous ulcers of Crohn's disease are identical to those seen endoscopically in patients with small intestinal (30) and colonic ischemia. Furthermore, evidence has recently been presented for the existence of a microangiopathic etiology of Crohn's disease (31). It is tempting, therefore, to suggest that oral contraceptives may be involved in the pathogenesis of the disease.

Several large studies involving over 50,000 oral contraceptive users have documented an increased risk of IBD (32). Oral contraceptive use may increase the risk of Crohn's disease by about 1.5 to $2 \%$. A similarly increased risk of ulcerative colitis has been documented by some - but not all-studies (33).

The risk, in real terms, means that about two of 10,000 women taking oral

8. Binder V, Hendriksen C, Kreiner S. Prognosis in Crohn's disease - based on results from a regional patient group from the county of Copenhagen. Gut 1985;26:146.

9. Mitchell A, Guyatt G, Singer J, et al. Quality of life in patients with inflammatory bowel disease. J Clin Gastroenterol 1988;10:306.

10. Wyke RJ. Capacity for work and employment record of patients with inflammatory bowel disease. Int Disabil Stud 1990:10:176.

11. Mallett SJ, Leonard Jones JE, Bingley J, Gibon E. Living with colitis. Lancet 1978;ii:619.

12. Monk M, Mendeloff AI, Siegel CI, Lilenfeld A. An epidemiological study of ulcerative colitis and regional enteritis among adults in Baltimore, Gastroenterology 1969;56:847.

13. Bonnevie O. A socio-economic study of patients with ulcerative colitis. Scand J Gastroenterol 1967;2:129.

14. Pinchbeck BR, Kirdeikis J, Thomson ABR. Epidemiology of ulcerative colitis and Crohn's disease. J Clin Gastroenterol 1988;10:505. contraceptives each year will develop ulcerative colitis compared with one of 10,000 who are nonusers. While the increase in risk is similar in Crohn's disease, the number of women developing the disease was even smaller because of the lesser incidence of this disease.

While objective data are lacking on the best course of action to pursue, it is preferable at present to discuss the situation with the patient. Some women are quite clear that in their circumstances the risk of unwanted pregnancy far outweighs the risks outlined above. Others feel that a trial discontinuation of oral contraceptives is appropriate and use alternate means of contraception.

\section{SUMMARY}

The overall picture which emerges is that individuals with IBD manage, despite the difficulties, to maintain normal function in their work, marital and social lives. While earlier studies suggested that the outlook was guarded, the more recent controlled studies, in which the IBD population is compared with the general population, suggest very little difference. The prospect of living a full and active life is not diminished by a diagnosis of IBD.

15. Drossman DA, Parrick DL, Mitchell CM, Zagami EA, Appelbaum MI.

Health-related quality of life in inflammatory bowel disease:

Functional status and patient worries and concerns. Dig Dis Sci 1989:34:1379.

16. Joachim G, Milne B. Inflammatory bowel disease: Effects on lifestyle. J Adv Nurs 1987;12:483.

17. Mayberry JF, Weterman IT. European survey of fertility and pregnancy in women with Crohn's disease: A case control study by European collaborative group. Gut 1986;27:821.

18. Gazzard BG, Price HL, Libby GW, Dawson AM. The social toll of Crohn's disease. Br Med J 1978:2:1117.

19. Edwards FC, Truelove SC. The course and prognosis of ulcerative colitis. Gut 1963:4:299.

20. Farmer RG, Michener WM. Prognosis of Crohn's disease with onset in childhood or adolescence. Dig Dis Sci 1979;24:752.

21. Meyers S, Walfish D, Sachar DB, 
Greenstein AJ, Hill AG, Janowitz HD. Quality of life after surgery for Crohn's disease: A psychosocial survey. Gastroenterology 1980;78:1-6.

22. DeDombal FT, Burton I, Galigner JC. The early and late results of surgical treatment for Crohn's disease. Br J Surg 1971;58:805.

23. Lask B, Jenkins J, Nabarro L, Booth I. Psychosocial sequelae of stoma surgery for inflammatory bowel disease in childhood. Gut 1987;28:1257.

24. Roy PH, Saver WG, Beaurs OH, Farron GM. Experience with ileostomies. Evaluation of long term rehabilitation in 497 patients. Am J Surg 1970;119:77.
25. Barnett WO. Current experiences with the continent intestinal reservoir. Surg Gynecol Obstet 1989;168:1.

26. Skarsgard ED, Atkinson KG, Bell GA, Pezim ME, Seal AM, Sharp FR.

Function and quality of life results after ileal pouch surgery for chronic ulcerative colitis and familial polyposis. Am J Surg 1989;157:467.

27. Calkins BM. A meta-analysis of the role of smoking in inflammatory bowel disease. Dig Dis Sci 1989;34:1841.

28. Sutherland LR, Ramcharan S, Bryant H, Fick G. Effect of cigarette smoking on recurrence of Crohn's disease. Gastroenterology 1990;98:1123.

29. Reeves G. Smoking and immunity.
Lancet 1990;335:1561-3.

30. MacIntosh DJ, Leddin DJ. Transient duodenal erosions in association with superior mesenteric ischemia. Can J Gastroenterol 1989;3:29.

31. Wakefield AJ, Sawyer AM, Drillon AP, et al. Pathogenesis of Crohn's disease - multifocal gastrointestinal infarction. Lancet 1989;ii: 1057.

32. Logan RFA, Kay CR, Scott L. Oral contraceptives, smoking and inflammatory bowel disease, findings in the RCGP oral contraceptive study. Int J Epidemiol 1989;18:105.

33. Rhodes JM, Cocrel R, Allan RN, Hawker PC, Dawson J, Elias E. Colonic Crohn's disease and use of oral contraceptives. Br Med ] 1984;288:595. 


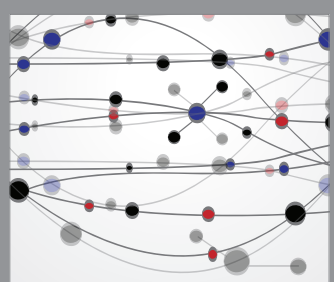

The Scientific World Journal
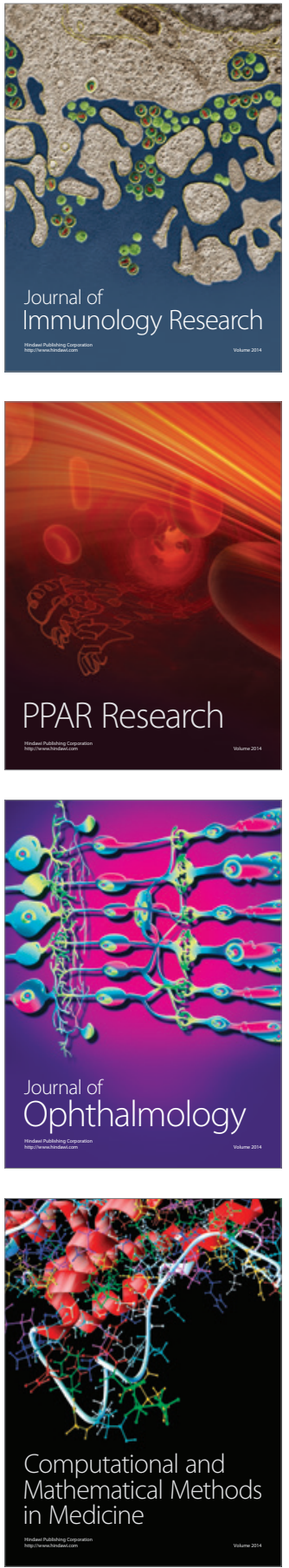

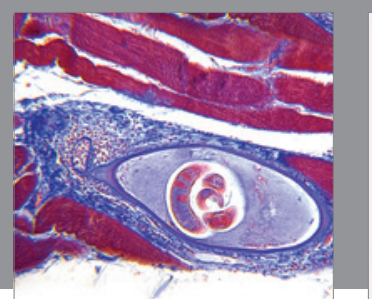

Gastroenterology Research and Practice

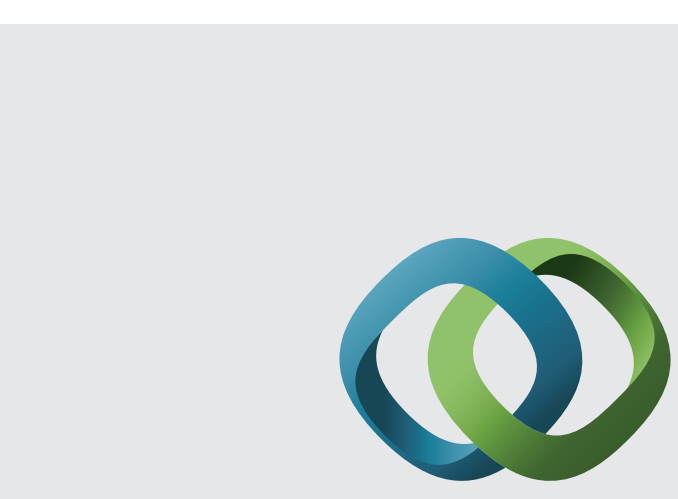

\section{Hindawi}

Submit your manuscripts at

http://www.hindawi.com
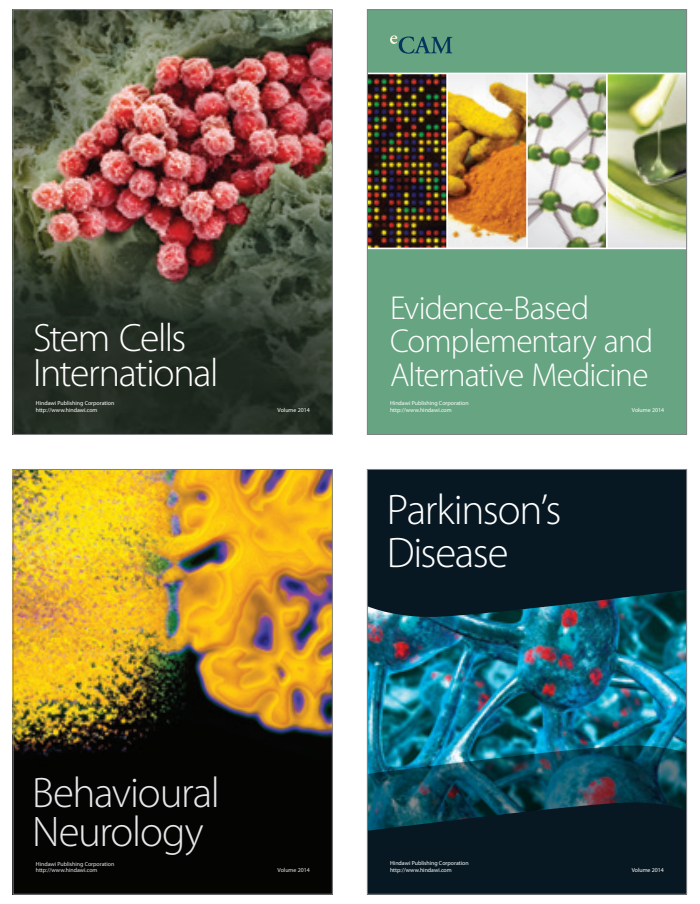
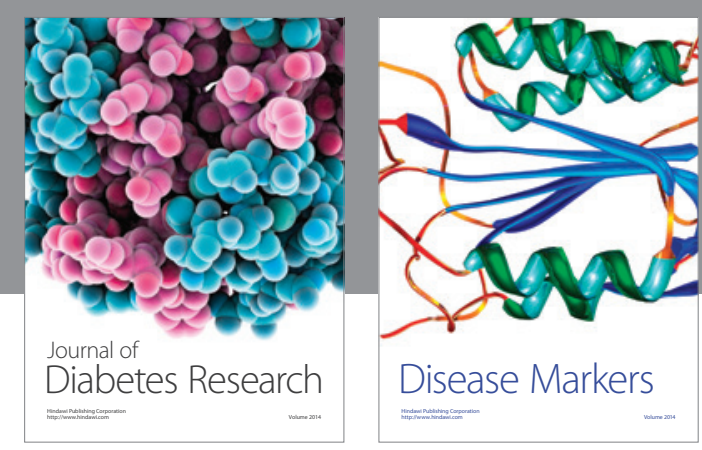

Disease Markers
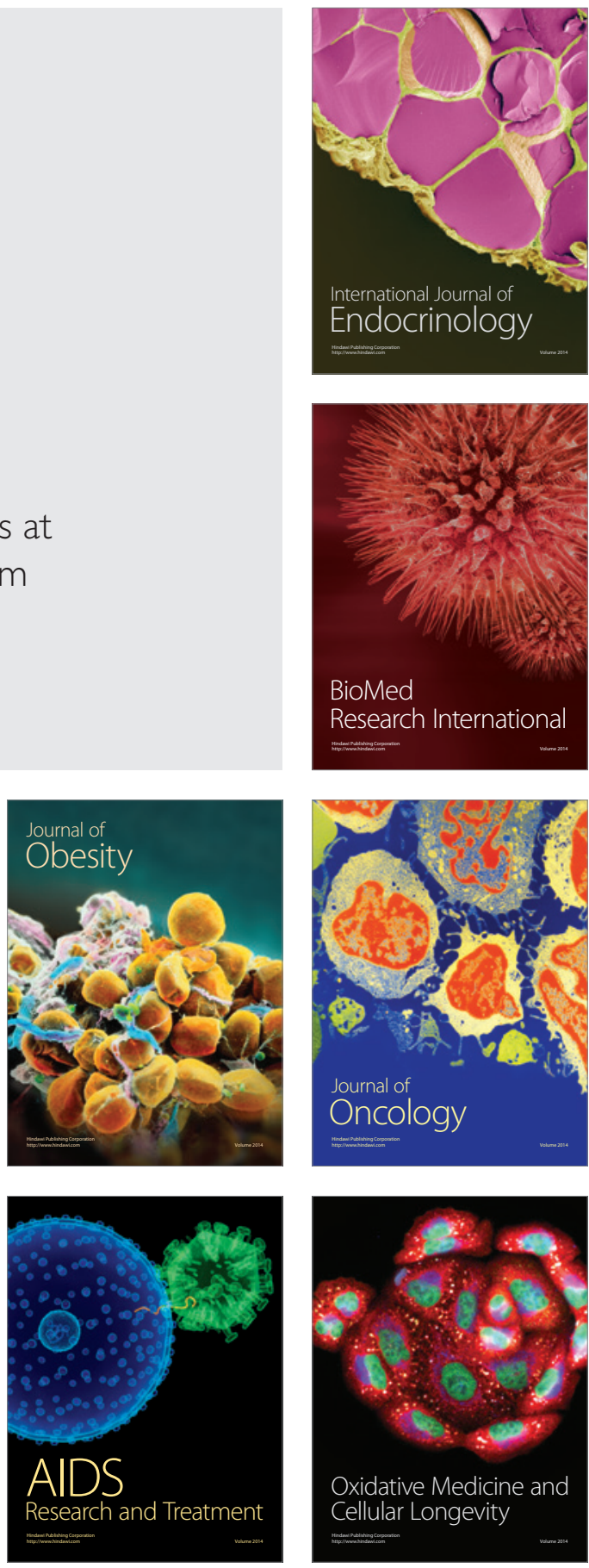